\title{
Inelastic Neutron Scattering Study of Brønsted Acidity and Water Confinement in Zeolites ${ }^{\dagger}$
}

\author{
Mónica Jiménez-Ruiz 1,*, Tetiana Lemishko 1, Susana Valencia 2, German Sastre ${ }^{2}$ and \\ Fernando $\operatorname{Rey}^{2}$ \\ 1 Institute Laue-Langevin, 71 Avenue des Martyrs, 38000 Grenoble, France \\ 2 Instituto de Tecnologia Quimica, Avda. Los Naranjos s/n, 46022 Valencia, Spain \\ * Correspondence: jimenez@ill.fr \\ + Presented at the 37th International Symposium on Dynamical Properties of Solids (DyProSo 2019), Ferrara, \\ Italy, 8-12 September 2019.
}

Published: 5 September 2019

Zeolites, crystalline and microporous aluminosilicates, are one of the most important groups of functional materials. Zeolites are widely used as solid acid catalysts in petroleum refinery and petrochemical industries. Zeolites can be described as microcoporous polymorphs of quartz. Whilst quartz is $\mathrm{SiO} 2$, zeolites asmit the isomorphous substitution of $\mathrm{Si}$ by many tetrahedrally coordinated atom, typically $\mathrm{Al}(\mathrm{Si} 4+$ à $\mathrm{Al} 3++\mathrm{H}+)$. In this way, the $\mathrm{Si} / \mathrm{Al}$ ratio gives the number of acid sites, but not their location and strength.The catalytic properties of a zeolite depend strongly on its acidity, and this in turns depends on: the total number of acid sites, their individual strength, and their individual location. These three factors are strongly correlated. Geometric parameters that are defined by the location of the acid site (i.e., bond angles and lengths around the acid site) make a remarkable contribution to the acid strength. It was found that the strong acid sites have the trend to be found in relatively small micropores [1].

In the present work we study the zeolite LTA Si/Al $=40$ (only one acid site per unit cell). The structure of LTA zeolite has the micropores consisting of large and small cavities. Inelastic neutron scattering (INS) has been used to study the acid sites of the LTA zeolite with different Si/Al ratios. There are two groups of bands: the first one found at $1050-1100 \mathrm{~cm}^{-1}$ that corresponds to the $\mathrm{SiOH}$ in-plane bending and another one found near $400-500 \mathrm{~cm}^{-1}$ which is attributed to the out-of-plane bending. These bending modes of the acid site are not no possible to measure with IR spectroscopy since these bands overlap with the strong bands from the zeolite framework. The combination of an extremely high quality of the samples and the sensitivity of the instrument allows to detect with high precision the acid sites of $\mathrm{LTA} \mathrm{Si} / \mathrm{Al}=40$ and obtain information about its position. In order to fully understand the INS spectra we performed ab-initio calculations [2,3].

In addition the polar properties of zeolites can be nicely tuned by selecting the appropriate chemical composition and concentration of structural defects in their frameworks. In the present study we were particularly interested about the mechanism of water adsorption on small pore zeolites and the influence of the polarity of the zeolite cavities in the clustering of water molecules when adsorbed in confined spaces, since there is controversy on the formation of hydroxonium cations when water is adsorbed on acid zeolites, and in case of hydroxonium formation, who many water molecules participate into the hydroxonium species. The simple framework of the chabazite makes this zeolite and ideal candidate for the INS study of adsorbed molecules with theoretical approaches in order to provide a deep understanding on the influence of the polarity of zeolite on the clustering of adsorbed water [4]. 


\section{References}

1. Katada, N.; Suzuki, K.; Noda, T.; Sastre, G.; Niwa, M. Correlation between Brønsted Acid Strength and Local Structure in Zeolites. J. Phys. Chem. C 2009, 113, 19208-19217.

2. Lemishko, T.; Valencia, S.; Rey, F.; Jiménez-Ruiz, M.; Sastre, G. Inelastic Neutron Scattering Study on the Location of Brønsted Acid Sites in High Silica LTA Zeolite. J. Phys. Chem. C 2016, 120, 24904-24909.

3. Lemishko, T.; Jiménez-Ruiz, M.; Rey, F.; Valencia, S.; Blasco, T.; Vidal Moya, A.; Sastre, G. Inelastic Neutron Scattering Study of the Aluminum and Brønsted Site Location in Aluminosilicate LTA Zeolites. J. Phys. Chem. C 2018, 122, 11450-11454.

4. Jimémez-Ruiz, M.; Gahle, D.; Lemishko, T.; Valencia, S.; Sastre, G.; Rey, F. Evidence of Hydronium Formation in Water-chabazite Zeolite Using INS experiments and ab-initio Molecular Dynamics Simulations. Manuscript in preparation.

(C) 2019 by the authors. Licensee MDPI, Basel, Switzerland. This article is an open access article distributed under the terms and conditions of the Creative Commons Attribution (CC BY) license (http://creativecommons.org/licenses/by/4.0/). 